\title{
Pengaruh Kualitas Pelayanan dan Persepsi Harga terhadap Kepuasan Pasien di Rumah Sakit Type C Kabupaten Kebumen
}

\author{
Muhyar Nugraha $^{1)}$, Sumadi $^{2}$ \\ 1), 2) Magister Manajemen Fakultas Ekonomi, Universitas Islam Indonesia, Yogyakarta \\ Email: dhethisulastri@yahoo.com ${ }^{l)}$
}

\begin{abstract}
ABSTRAK
Kebutuhan masyarakat terus berkembang menyikapi kemajuan dalam masyarakat seperti kebutuhan akan pelayanan kesehatan, karena kesehatan merupakan salah satu kebutuhan hidup yang penting dalam menunjang aktifitas seseorang. Kemajuan dan perkembangan rumah sakit akan sangat tergantung dari kualitas pelayanan yang diberikan. Jika pelayanan yang diberikan baik maka pasien di rumah sakit tersebut akan merasa puas. Menelaah masalah kualitas pelayanan terutama pelayanan kesehatan di rumah sakit tidaklah mudah karena disatu sisi mempunyai tanggung jawab sosial dengan memberikan pelayanan kesehatan secara manusiawi, tetapi di sisi lain juga harus memperhatikan prinsipprinsip ekonomi menyangkut penyelenggaraan rumah sakit yang memerlukan biaya investasi, operasional dan pemeliharaan yang begitu besar. Metode pengambilan data ini menggunakan kuesioner, Pengambilan sampel penelitian dengan metode non-probability sampling dengan jumlah sampel 150 responden. Analisis yang digunakan menggunakan analisis deskriptif dan analisis regresi linear berganda. Ada pengaruh kualitas layanan dan harga terhadap kepercayaan pasien sebesar 81,7\% sedangkan sisanya 18,3\% dipengaruhi oleh variabel lain yang tidak dimasukan ke dalam penelitian ini.
\end{abstract}

Kata Kunci: Kualitas Pelayanan, Harga, Kepuasan Pasien

\section{Pendahuluan}

Kebutuhan masyarakat akan kesehatan terus berkembang. Menyikapi kemajuan dalam hal kesehatan, masyarakat membutuhkan pelayanan kesehatan yang sangat lengkap dan memadai karna kesehatan merupakan hal yang sangat penting untuk menunjang kegiatan seseorang. Pelayanan medis atau Penyedia jasa pelayanan kesehatan harus mampu memberikan penyembuhan penyakit dan pemulihan kesehatan untuk meningkatkan mutu pelayanan yang berorientasi kepada kepuasan pasien.

Kondisi lingkungan usaha yang ada disekitar masyarakat, menuntut perusahaan kepada kenyataan bahwa kualitas menjadi suatu keharusan agar perusahaan tetap sukses baik ditingkat operasional, manajerial maupun strategik, karena kualitas merupakan salah satu faktor yang menentukan bagi perusahaan agar konsumen merasa puas dan dapat bersaing dengan perusahaan lain. Kepuasan merupakan kunci sukses bagi perusahaan yang ingin mendapatkan kepercayaan dari konsumen.

Kemajuan dan perkembangan rumah sakit akan sangat tergantung dari kualitas pelayanan yang diberikan. Jika pelayanan yang diberikan baik maka pasien di rumah sakit tersebut akan merasa puas. Peran dokter, perawat, maupun staf lain di rumah sakit sangat penting. Perawat sebagai salah satu tenaga kesehatan di rumah sakit merupakan salah satu komponen dalam pelayanan di rumah sakit dan menjadi tolak ukur yang menentukan kualitas pelayanan kesehatan di rumah sakit.

Peningkatan kualitas pelayanan pada rumah sakit dapat dilakukan dengan pendekatan institutional atau individu. Peningkatan kualitas pelayanan ini dapat dilakukan dengan dua cara, yaitu dengan meningkatkan kualitas dan kuantitas sumber daya, tenaga, biaya, perlengkapan, dan material yang diperlukan dengan menggunakan teknologi tinggi. Salah satu cara yang lainnya adalah dengan memperbaiki proses pelayanan.

Untuk dapat menentukan kebijakan pelayanan yang tepat, khususnya dalam pelayanan kepada pasien, diperlukan kajian tentang dimensi kualitas pelayanan kepada pasien. Sehubungan dengan kondisi itu, permasalahannya adalah apakah lima demensi yang menentukan kualitas pelayanan perusahaan jasa yaitu variabel reliability (keterhandalan), responsiveness (cepat tanggap), assurance (jaminan), empathy (empati), dan tangible (nyata) akan mempengaruhi kepuasan pasien khususnya pasien Rumah Sakit Purbowangi Gombong.

Berdasarkan paparan latar belakang, maka rumusan masalah dalam penelitian ini adalah bagaimana pengaruh kualitas pelayanan dan persepsi harga terhadap kepuasan pasien di rumah sakit type C di Kabupaten Kebumen.

Tujuan Penelitian ini adalah untuk mengetahui Pengaruh Kualitas Pelayanan dan Persepsi Harga terhadap Kepuasan Pasien di Rumah sakit Type C di Kabupaten Kebumen.

\section{Tinjauan Pustaka Kepercayaan}

Menurut Mowen dan Minor (2001), kepercayaan pelanggan adalah semua pengetahuan yang dimiliki oleh pelanggan dan semua kesimpulan yang dibuat pelanggan tentang objek, atribut, dan manfaatnya. Objek dapat berupa produk, orang, perusahaan, dan segala sesuatu dimana seseorang memiliki kepercayaan dan sikap. Atribut adalah karakteristik atau fitur yang mungkin dimiliki atau tidak dimiliki oleh objek.

Penelitian berjudul "Customer satisfaction, trust and commitment as predictors of customer loyalty within an 
optometric practice environment" oleh Vuuren et al. (2012) mengemukakan bahwa hubungan dapat dilihat sebagai sebuah seri dari transaksi yang menimbulkan kewaspadaan dari hubungan bersama melalui kepercayaan dan komitmen. Level kepercayaan dan komitmen yang tinggi dapat mempengaruhi keputusan pembelian oleh konsumen dan dapat meningkatkan profitabilitas organisasi.

Kepercayaan adalah faktor penting untuk mempengaruhi hubungan antara komitmen dan loyalitas konsumen. Ketika salah satu pihak telah memberikan kepercayaannya maka pihak lainnya harus memberikan dan mengembangkan perilaku positive terhadap pihak yang lain. Ketika konsumen percaya terhadap perusahaan maka konsumen secara tidak langsung akan melakukan pembelian ulang di perusahaan. Meningkatnya rasa percaya konsumen terhadap perusahaan akan membuat hubungan yang sukses diantara perusahaan dan konsumen.

Alrubaiee (2011) dengan penelitian berjudul "The Mediating Effect of Patient Satisfaction in the Patients' Perceptions of Healthcare Quality-Patient Trust Relationship" Trust dapat didefinisikan sebagai kepercayaan antara satu pihak kepada pihak lain yaitu antara perusahaan dengan konsumen.

\section{Kepuasan Konsumen}

Kepuasan konsumen adalah sejauh mana manfaat sebuah produk dirasakan (perceived) sesuai dengan apa yang diharapkan pelanggan (Amir, 2005).

Oliver (dalam Peter dan Olson, 1996) menyatakan bahwa kepuasan pelanggan adalah rangkuman kondisi psikologis yang dihasilkan ketika emosi yang mengelilingi harapan tidak cocok dan dilipatgandakan oleh perasaanperasaan yang terbentuk mengenai pengalaman pengkonsumsian. Westbrook \& Reilly (dalam Tjiptono, 2005) mengemukakan bahwa kepuasan konsumen merupakan respon emosional terhadap pengalaman yang berkaitan dengan produk atau jasa yang dibeli.

Gaspers (dalam Nasution, 2005) mengatakan bahwa kepuasan konsumen sangat bergantung kepada persepsi dan harapan konsumen. Adapun faktor-faktor yang mempengaruhi persepsi dan harapan konsumen antara lain:

a. Kebutuhan dan keinginan yang berkaitan dengan halhal yang dirasakan konsumen ketika sedang mencoba melakukan transaksi dengan produsen produk.

b. Pengalaman masa lalu ketika mengkonsumsi produk dari perusahaan maupun pesaing-pesaingnya.

c. Pengalaman dari teman-teman.

\section{Kualitas Pelayanan}

Kualitas adalah keseluruhan ciri dan sifat dari suatu produk atau pelayanan yang berpengaruh pada kemampuannya untuk memuaskan kebutuhan yang dinyatakan atau yang tersirat (Kotler, 2005).

Kualitas pelayanan dapat dicapai dengan menetapkan dan mengendalikan karakteristik mutu pelayanan serta karakteristik penghantaran pelayanan.
Karakteristik mutu pelayanan adalah ciri pelayanan yang dapat diidentifikasi, yang diperlukan untuk mencapai kepuasan konsumen. Ciri tersebut dapat berupa psikologis, orientasi waktu, etika dan teknologi (Siregar, 2004).

Menurut Mosahab et al. (2010) dengan penelitian berjudul "Service Quality, Customer Satisfaction, and Loyalty: A Test of Mediation" mengemukakan bahwa Kualitas layanan yang diberikan oleh perusahaan kepada konsumen merupakan faktor kompetitif yang paling penting dalam dunia bisnis di era ini. Penelitian-penelitian sebelumnya (Aprianto, 2016; Hildayanti, Marnisah, \& Dinata, 2018; Yanti, Karim, \& Wadud, 2018; Pebrianti \& Porwani, 2018; Aditia, Wadud, \& DP, 2002; Pribadi, 2020; Amha, 2020; Oktareza, Halin, \& Handayani, 2020) juga membuktikan bahwa kualitas pelayanan memengaruhi kepuasan konsumen.

\section{Harga}

Harga merupakan bagian yang sangat penting dalam pemasaran suatu produk karena harga adalah salah satu dari empat elemen utama dalam bauran pemasaran $(4 P=$ Product, Price, Place, Promotion). Price adalah jumlah uang yang harus dibayar oleh pelanggan untuk memperoleh produk.

Harga merupakan salah satu penentu keberhasilan suatu perusahaan karena harga menentukan seberapa besar keuntungan yang akan diperoleh perusahaan dari penjualan produknya baik berupa barang jasa (Irawan, Marnisah, \& Azrai'e, 2018; Arifai \& Trihandayani, 2018; Batu, Suryani, Septia, \& Sekaryahya, 2020). Menetapkan harga terlalu tinggi akan menyebabkan maupun penjualan menurun, namun jika harga terlalu rendah akan mengurangi keuntungan yang dapat diperoleh organisasi perusahaan. Selain itu, harga merupakan salah satu faktor dalam atribut ekstrinsik yang menentukan persepsi konsumen akan kualitas dan kaitannya dengan keputusan pembelian konsumen.

\section{Metode Penelitian}

Objek penelitian adalah kepuasan pasien Rumah Sakit Type C di Kabupaten Kebumen yaitu Rumah sakit Purbowangi dan Rumah sakit Purwogondo, metode pengambilan sampel yang digunakan pada penelitian ini adalah metode non-probabilty sampling. Sampel pada penelitian ini adalah pasien rawat inap di Rumah sakit Purbowangi dan RS Purwogondo dengan jumlah sampel 150 orang. Variable pada penelitian ini menggunakan 2 jenis variable yaitu variable bebas (kualitas pelayanan, harga) dan variable terikat (Kepercayaan dan Kepuasan Konsumen).

Instrument pada penelitian ini adalah menggunakan kuesioner dan Skala Likert. Uji Instrument penelitian menggunakan Uji Validitas dan Realibitas, Uji validitas menggunakan pendekatan atau formulasi Pearson Correlation (r) atau product Moment, pada butir pertanyaan berjumlah 20 pertanyaan dan semua pertanyaan didapatkan hasil valid dengan batas kriteria penerimaan adalah 0.05. Sedangkan untuk uji Realibitas 
menggunakan formulasi Alpha Cronbach (Sugiyono, 2010).

Pengujian validitas dan reabilitas pada penelitian ini dilakukan pada 30 Responden dengan taraf nyata sebesar 0.05 atau 5\%, perhitungan menggunakan pendekatan SPSS. Pada penelitian ini analisis data menggunakan analisis deskriptif dan analisis Regresi. Analisis deskriptif yaitu analisis dengan merinci dan menjelaskan keterkaitan data penelitian dalam bentuk kalimat, sedangkan analisis regresi pada penelitian ini menggunakan anlisis regresi berganda dimana persamaan regresi ini mengandung unsur interaksi dua variable independent.

\section{Hasil dan Pembahasan \\ Hasil Penelitian}

Penelitian ini dilakukan di 2 rumah sakit type $\mathrm{C}$ yaitu rumah sakit RSU Purbowangi dan RSU Purwogondo.

\section{Objek Penelitian}

Tabel 1. Karakterisrik Responden Berdasarkan Jenis Kelamin di RS Type C di Kabupaten Kebumen

\begin{tabular}{cccc}
\hline No & Jenis Kelamin & f & $\%$ \\
\hline 1. & Laki-Laki & 71 & 47,3 \\
2. & Perempuan & 79 & 52,7 \\
\hline & Total & 150 & 100 \\
\hline
\end{tabular}

Sumber: Data Primer yang Diolah 2018

Tabel 1 di atas menjelaskan bahwa dari 150 responden jenis kelamin responden yang paling banyak adalah perempuan yaitu sebesar 52,7 \% dan sisanya adalah berjenis kelamin laki-laki 47,3\% dengan demikian dapat disimpulkan bahwa responden penilitian yang paling banyak berdasarkan jenis kelamin adalah perempuan.

Tabel 2. Karakterisrik Responden Berdasarkan Usia di RS Type $C$ di Kabupaten Kebumen

\begin{tabular}{cccc}
\hline No & Usia & f & $\%$ \\
\hline 1. & $20-24$ th & 8 & 5,3 \\
2. & $25-35$ th & 38 & 25,3 \\
3. & $36-45$ th & 46 & 30,7 \\
4. & $>45$ th & 58 & 38,7 \\
\hline & Total & 150 & 100 \\
\hline
\end{tabular}

Sumber: Data Primer yang Diolah 2018

Tabel 2 diatas menunjukan bahwa dari 150 responden yang paling banyak responden adalah di usia lebih dari 45 tahun sebesar 38,7\%.

Tabel 3. Karakterisrik Responden Berdasarkan Pendidikan di RS Type C di Kabupaten Kebumen

\begin{tabular}{cccc}
\hline No & Pendidikan & f & $\%$ \\
\hline 1. & SSMU & 96 & 64 \\
2. & SMU & 24 & 16 \\
3. & Diploma & 2 & 1,3 \\
4. & Sarjana & 0 & 0 \\
5. & Lain-lain & 28 & 18,7 \\
\hline & Total & 150 & 100 \\
\hline
\end{tabular}

Sumber: Data primer yang diolah 2018
Tabel 3 diatas menjelaskan bahwa total 150 responden yang berpendidikan paling banyak adalah $<$ SMU sebesar $64 \%$ responden.

Tabel 4. Karakterisrik Responden Berdasarkan Pekerjaan di RS Type C di Kabupaten Kebumen

\begin{tabular}{cccc}
\hline No & Pekerjaan & f & $\%$ \\
\hline 1. & PNS & 6 & 4 \\
2. & Swasta & 10 & 6,7 \\
3. & Wiraswasta & 65 & 43,3 \\
4. & Lain-lain & 69 & 46 \\
\hline & Total & 150 & 100 \\
\hline
\end{tabular}

Sumber: Data Primer yang Diolah 2018

Tabel 4 diatas menjelaskan bahwa 150 responden pekerjaan responden yang paling banyak adalah lain-lain seperti buruh, petani dan ibu rumah tangga sebesar $46 \%$.

Tabel 5. Karakterisrik Responden Berdasarkan Pendapatan di RS Type C di Kabupaten Kebumen

\begin{tabular}{cccc}
\hline No & Pendapatan & $\mathrm{f}$ & $\%$ \\
\hline 1. & $<1 \mathrm{Jt}$ & 34 & 22,7 \\
2. & $1-1,5 \mathrm{jt}$ & 100 & 66,7 \\
3. & $1,6-3 \mathrm{jt}$ & 12 & 8,0 \\
4. & $>3 \mathrm{jt}$ & 4 & 2,7 \\
\hline & Total & 150 & 100 \\
\hline
\end{tabular}

Sumber: Data Primer yang Diolah 2018

Tabel 5 diatas menjelaskan bahwa 150 responden dilihat dari pendapatan yaitu paling besar adalah di ratarata pendapatannya $1-1,5$ juta sebesar $66,7 \%$.

Analisis Pengaruh Kualitas Pelayanan, Persepsi Harga terhadap Kepuasan Pasien di RS Type C di Kabupaten Kebumen

Prasyarat Kesesuaian Data (Goodness Of Fit)

Sebelum dilakukan analisis statistik, terlebih dahulu dilakukan uji persyaratan yang meliputi uji normalitas, Uji Multikolinieritas, Uji Autokorelasi, Uji Heteroskedastisitas dan Uji Koefisien Determinasi $\left(\mathrm{R}^{2}\right)$.

Tabel 6. Rangkuman Hasil Uji Normalitas (KolmogorovSmirnov)

\begin{tabular}{lccl}
\hline \multicolumn{1}{c}{ Variabel } & K-s Z & $p$ value & Keterangan \\
\hline Kualitas & 1,331 & 0,058 & Normal \\
Harga & 1,304 & 0,067 & Normal \\
Kepercayaan & 1,191 & 0,117 & Normal \\
Kepuasan & 1,352 & 0,052 & Normal \\
\hline
\end{tabular}

Sumber: Analisis Data Primer, 2018

Berdasarkan hasil di atas diperoleh nilai signifikansi (p) masing-masing variabel $>0,05$, sehingga dapat disimpulkan bahwa distribusi data kualitas, harga, kepercayaan dan kepuasan dinyatakan normal. 
Tabel 7. Uji Multikolinearitas

\begin{tabular}{|c|c|c|c|c|}
\hline No & $\begin{array}{c}\text { Variabel } \\
\text { Bebas }\end{array}$ & Tolerance & VIF & Keterangan \\
\hline 1 & Kualitas & 0,184 & 5,439 & $\begin{array}{c}\text { Non } \\
\text { multikolineritas }\end{array}$ \\
\hline 2 & Harga & 0,328 & 3,052 & $\begin{array}{l}\text { Non } \\
\text { multikolineritas }\end{array}$ \\
\hline 3 & Kepercayaan & 0,183 & 0,183 & $\begin{array}{l}\text { Non } \\
\text { multikolineritas }\end{array}$ \\
\hline
\end{tabular}

Heteroskedastistas akan mengakibatkan penaksiran koefisien regresi menjadi tidak efisien. Pada penelitian ini dilihat bahwa terjadi heterokesdastistas karena terdapat pola yang jelas.

\section{Uji Autokorelasi}

Hasil analisis dalam penelitian ini menunjukkan nilai Durbin Watson adalah sebesar 1,950. Nilai Durbin Watson berada diantara du dan 4-dU (dU=1,7741; 4-dU= 2,2259) yang menunjukkan bahwa tidak terdapat autokorelasi pada model regresi penelitian ini.

Pengaruh Kualitas Pelayanan dan Harga terhadap Kepercayaan

Tabel 8. Hasil Analisis Regresi Pengaruh Kualiatas Layanan dan Harga terhadap Kepercayaan Pasien

\begin{tabular}{lccc}
\hline \multicolumn{1}{c}{ Variabel } & $\begin{array}{c}\text { Koefisien } \\
\text { Standardized }\end{array}$ & $\boldsymbol{P}$ & Kesimpulan \\
\hline $\begin{array}{l}\text { Kualitas } \\
\quad \text { layanan }\end{array}$ & $+0,703$ & 0,000 & Signifikan \\
$\quad$ X1) & & & \\
$\begin{array}{l}\text { Harga }(\mathrm{X} 2) \\
\mathrm{F}=327,353\end{array}$ & $+0,237$ & 0,000 & Signifikan \\
$\mathrm{R}^{2}=0,817$ & & 0,000 & Signifikan \\
\hline
\end{tabular}

Sumber : analisis data primer, 2018

Berdasarkan output analisis pada tabel 8 diketahui nilai $\mathrm{R}^{2}$ adalah 0,817 , Menunjukkan bahwa persentase pengaruh variabel independen (kualitas layanan dan harga) terhadap variabel dependen (kepercayaan pasien) sebesar $81,7 \%$, sedangkan sisanya $18,3 \%$ dipengaruhi oleh variabel lain.

Hasil uji F pada tabel 8 mempunyai nilai 327,353 dengan nilai signifikansi 0,000 , menunjukkan bahwa kualitas layanan dan harga secara bersama-sama berpengaruh terhadap kepercayaan konsumen sehingga model regresi berganda sesuai untuk melakukan analisis pengaruh kualitas pelayanan dmn an harga adalah signifikan terhadap kepercayaan pasien di RS Type C Kabupaten Kebumen sebagaimana hasil analisis mempunyai nilai $p$ value $0,000<0,05$.

\section{Pengaruh Kualitas Pelayanan, Kepercayaan dan Harga terhadap Kepuasan Pasien}

Berdasarkan tabel 9 diketahui kualitas berpengaruh dan harga secara bersama-sama berpengaruh signifikan terhadap kepercayaan pasien.
Tabel 9. Hasil Analisis Regresi Pengaruh Kualiatas Layanan, Kepercayaan dan Harga terhadap Kepuasan Pasien

\begin{tabular}{cccc}
\hline Variabel & $\begin{array}{c}\text { Koefisien } \\
\text { Standardized }\end{array}$ & $\boldsymbol{P}$ & $\begin{array}{c}\text { Kesimpula } \\
\mathbf{n}\end{array}$ \\
\hline $\begin{array}{c}\text { Kualitas } \\
\text { layanan } \\
\text { (X1) }\end{array}$ & $+0,576$ & 0,000 & Signifikan \\
$\begin{array}{c}\text { Kepercayaan } \\
\text { pasien }\end{array}$ & $+0,163$ & 0,000 & Signifikan \\
$\quad(\mathrm{X} 2)$ & & & \\
$\begin{array}{l}\text { Harga (X3) } \\
\mathrm{F}=1177,56\end{array}$ & $+0,288$ & 0,000 & Signifikan \\
$\mathrm{R}^{2}=0,960$ & 0,000 & Signifikan \\
\hline Sumber : analisis data primer, 2018 & & \\
\end{tabular}

\section{Pembahasan}

Pernyataan hipotesis pertama dalam penelitian ini adalah kualitas layanan berpengaruh positif terhadap kepercayaan pasien. Hasil analisis menunjukkan bahwa pelayanan pasien mempunyai koefisien bernilai positif sebesar $+0,703$ dengan nilai signifikansi 0,000 . Hal tersebut menunjukkan bahwa terdapat pengaruh kualitas pelayanan berpengaruh terhadap kepercayaan pasien di RS Type C Kabupaten Kebumen. Hasil penelitian ini sesuai dengan hasil penelitian Elrado et al., (2014) yang menyatakan bahwa kualitas pelayanan berpengaruh signifikan terhdap kepercayaan konsumen. Adanya kualitas pelayanan yang baik akan menciptakan kepercayaan konsumen bahwa pelayanan yang diberikan adalah baik.

Hipotesis kedua adalah adanya pengaruh yag signifikan antara harga terhadap kepercayaan pasien. Hasil analisis menunjukkan variabel harga mempunyai koefisien bernilai positif yaitu $+0,237$ dengan nilai signifikansi 0,000. Hasil penelitian ini mendukung penelitian Suherman (2016) yang menyatakan bahwa harga secara signifikan berpengaruh terhadap kepercayaan konsumen.

Hipotesis ketiga adalah menyatakan bahwa kualitas layanan berpengaruh positif terhadap kepuasan pasien. Hasil analisis memperlihatkan variebel pelayanan pasien mempunyai koefisien bernilai positif dengan nilai $+0,576$ dan signifikansi 0,000. Hasil penelitian tersebut didukung oleh hasil penelitian Mosahab et al. (2010) dengan penelitian berjudul "Service Quality, Customer Satisfaction, and Loyalty: A Test of Mediation" yang mengemukakan bahwa Kualitas layanan yang diberikan oleh perusahaan kepada konsumen merupakan faktor kompetitif yang paling penting dalam dunia bisnis.

Hipotesis keempat pada penelitian ini adalah adanya pengaruh positif antara kepercayaan terhadap kepuasan pasien. Hasil persamaan regresi menunjukkan bahwa variebel kepercayaan mempunyai koefisien bernilai positif $+0,163$ dengan nilai signifikansi 0,000 . Hasil penelitian ini sesuai dengan Alrubaiee (2011) yang menunjukkan hasil bahwa kepercayan pasien berpengaruh terhadap kepuasan pasien.

Variabel harga berpengaruh positif terhadap kepuasan pasien. Hasil analisis menunjukkan bahwa variabel harga 
mempunyai koefisien bernilai positif $+0,288$ dengan nilai signifikansi 0,000 . Harga akan berpengaruh positif dalam meningkatkan kepuasan pasien di RS Type C Kabupaten Kebumen. Pengaruh variabel harga yang signifikan terhadap kepuasan pasien didukung oleh hasil penelitian Rahma (2012) yang menyatakan bahwa harga berpengaruh terhadap kepuasan.

\section{Penutup \\ Kesimpulan}

Ada pengaruh yang signifikan antara Kualitas Pelayanan dan Persepsi Harga terhadap Kepuasan Pasien di RS Type C di Kabupaten Kebumen

\section{Saran}

Peneliti selanjutnya diharapkan agar peneliti selanjutnya menggunakan hasil penelitian ini sebagai sumber tulisan ilmiah terpilih untuk menginsipirasi penelitian serupa. Penelitin selanjutnya diharapkan mampu mengkaji lebih dalam lagi atau dengan menambah kan variable lainnya, menambahkan lebih banyak tempat penelitiannya dan sampel yang di gunankan lebih banyak lagi.

\section{Daftar Pustaka}

Aditia, A. R. R., Wadud, M., \& DP, M. K. (2020). Pengaruh Kualitas Produk terhadap Kepuasan Konsumen Sepeda Motor NMAX pada PT Yamaha A. Rivai Palembang. Jurnal Nasional Manajemen Pemasaran \& SDM, 1(01), 23-37. https://doi.org/10.47747/jnmpsdm.v1i01.4

Alrubaiee, L. 2011. The Mediating Effect of Patient Satisfaction in the Patients' Perceptions of Healthcare Quality - Patient Trust Relationship. International Journal of Marketing Studies. Vol 3 No 1.

Amha, G. G. (2020). Determinants of Customer Satisfaction and Customer Loyalty in Amhara Credit and Saving Institute (ACSI): The Case of Waghimera Zone Sekota Town. International Journal of Marketing \& Human Resource Research, 1(01), 34-51. Retrieved from http://journal.jisinstitute.org/index.php/ijmhrr/article/view/70

Aprianto, R. (2016). Pengaruh Pelayanan Terhadap Kepuasan Nasabah Pada Kantor PT Bank Bca Cabang Lubuklinggau. Jurnal Ilmiah Ekonomi Global Masa Kini, 7(1), 11-18.

Arifai, A. A., \& Trihandayani, Z. (2018). Harga, Kualitas Produk dan Merek terhadap Keputusan Pembelian Tas KW Cartier di Kalangan Mahasiswi sebagai Penunjang Penampilan Kuliah. Jurnal Ilmiah Ekonomi Global Masa Kini, 8(3), 16-22.

Asri, V. I. 2013. Analisis Faktor - Faktor yang Mempengaruhi Loyalitas Pelanggan (Studi Kasus: Bank BRI Syariah Cabang Kudus). JOIR. Vol XII No. 2.

Azwar, A. 1996. Program Menjaga Mutu Pelayanan Kesehatan (Aplikasi Prinsi Lingkungan Pemecahan Masalah). Jakarta: Yayasan Penerbit IDI.
Barney, J.B., \& Hansen, M. H. 1994. Trustwor-thiness as a Source of Competitive Advantage. Journal of Strategic Management, Vol. 15.

Batu, R. L., Suryani, N. I., Septia, N., \& Sekaryahya, P. F. (2020). Pengaruh Harga dan Inovasi Layanan Aplikasi terhadap Keputusan Penggunaan Jasa Taksi Express: Survei pada Pengunduh Aplikasi Express Taxis. Jurnal Nasional Manajemen Pemasaran \& SDM, 1(01), 1-22. https://doi.org/10.47747/jnmpsdm.v1i01.6

Elrado, MH., Srikandi K., dan Edy, Y. (2014). "Pengaruh Kualitas Layanan Terhadap Kepuasan, Kepercayaan, dan Loyalitas pada Pelanggan Jambuwuluk Resort". Jurnal Administrasi Bisnis (JAB), Vol. 15 No. 2 Oktober 2014.

Engel, JF. Roger D. Blackwell dan Paul W. Miniard, 1994, "Perilaku Konsumen", Jilid 1, Edisi VI, Jakarta: Binarupa Aksara

Garbarino \& Huber. FJ. 1999. The Evolution of Loyalty Intentions. Journal of Marketing. Vol 7 No 2.

Ghozali, I, 2005. Aplikasi Analisis Multivarite dengan SPSS, Cetakan Keempat. Semarang: Badan Penerbit Universitas Diponegoro.

Giese \& Cote. 2000. Academy of Marketing Science Review. Defining Consumer Satisfaction.Vol2000 No. 1 Available: http://www.amsreview.org/articlesgiese012000.pdf.

Hildayanti, S. K., Marnisah, L., \& Dinata, E. S. (2018). Pengaruh Nilai, Kualitas Pelayanan dan Komitmen Organisasi Terhadap Kepuasan Pelanggan Pada PT. Asuransi Kresna Mitra Tbk Cabang Palembang. Jurnal Ilmiah Ekonomi Global Masa Kini, 9(1), 6170.

Indriantoro, N \& Bambang S. 1999. Metodologi Penelitian Bisnis. Cetakan Pertama. BPFE Yogyakarta.

Irawan, D., Marnisah, L., \& Azrai'e, K. R. (2018). Analisis Produk dan Harga terhadap Keputusan Mahasiswa Universitas IGM Membeli Smartphone Samsung. Jurnal Ilmiah Ekonomi Global Masa Kini, 8(2), 35-41.

Kotler, P, 1994, Manajemen Pemasaran, Analisis Perencanaan, Implementasi dan Pengendalian, Edisi Kedelapan, Jilid I, Fakultas Ekonomi UI, Jakarta.

Kotler, P. 2005. Manajamen Pemasaran, Jilid 1 dan 2. Jakarta: PT. Indeks Kelompok Gramedia.

Kotler, P. 2000. Manajemen Pemasaran "Pemasaran, Implikasi, dan Pengendalian”. Jakarta: Salemba Empat.

Kotler, P dan Keller, K.L. 2016. Marketing Management 15 ed. Global Edition. England. Pearson Education.

Mosahab, R, Osman M, T. Ramayah. 2010. Service Quality, Customer Satisfaction and Loyalty: A Test of Mediation. International Business Research. Vol 3 No 4.

Mowen, JC \& Michael M. 2002. Perilaku Konsumen. Jakarta: Erlangga. 
Nasution, M. Nur. 2004. Manajemen Jasa Terpadu. Bogor: Ghalia Indonesia.

Nasution, M. Nur. 2005. Manajemen Mutu Tepadu (Total Quality Management), Edisi Kedua, 2005, Ghalia Indonesia, Jakarta.

Oktareza, M. E. T., Halin, H., \& Handayani, S. (2020). The Effect of Service on Customer Satisfaction at PT Pandu Siwi Sentosa. International Journal of Community Service \& Engagement, 1(01), 19-26. Retrieved from http://journal.jisinstitute.org/index.php/ijcse/article/view/74

Parasuraman, A., Zeithalm, V., dan Berry L., 1988. SERVQUAL: A Multiple item Scale for Measuring Consumer Perceptions of Service Quality. Journal of Retaliling.

Parasuraman, A., Zeithalm, V., dan Berry L., 1985. Journal of Marketing: A Conceptual Model A of Service Quality and Its Implication for Future Research.

Pebrianti, T., \& Porwani, S. (2018). Persepsi Kepuasan Pasien Rawat Jalan terhadap Pelayanan Petugas di Bagian Pendaftaran Pada Puskesmas Sematang Borang Palembang. Jurnal Ilmiah Ekonomi Global Masa Kini, 8(2), 18-25.

Peter, J and Olson, J.C. 2010. Consumer Behavior. Edisi 9. New York: McGraw Hill Irwin.

Pramana, I Gede Yogi dan Ni Made Rastini. (2016). Pengaruh Kualitas Kepercayaan Nasabah dan Loyalitas Nasabah Bank Mandiri. E-Jurnal Manajemen Unu, Vol. 5, No.1, 2016: 706-733 ISSN: 2302-8912.

Pribadi, G. (2020). Service Quality sebagai Pengukuran Kepuasan Siswa dan Orang Tua/Wali Murid SMP Muhammadiyah 1 Gombong. Jurnal Ilmiah Ekonomi Global Masa Kini, 11(1).

Rahman, Muhammad Sabbir. 2012. "Service Quality, Corporate Image and Customer's Satisfaction Towards Customers Perception: An Exploratory Study on Telecom Customers in Bangladesh. Business Intelligence Journal - January, 2012 Vol.5 No.1.

Sekaran, U. 2010. Research Methods for Business: A Skill Building Approach. New Jersey: John Willey.

Siregar, D. D. 2004, Manajemen Aset, PT. Gramedia Pustaka Utama, Jakarta.

Sugiyono. 2010. Metode Penelitian Kuantitatif, Kualitatif dan $R \& D$. Bandung: Alfabeta.

Suherman, M (2016). Pengaruh Kualitas Layanan dan Harga terhadap Kepercayaan Konsumen serta Implikasinya pada Keputusan Pembelian (Studi Produk PosPay PLN) pada PT Pos Indonesia. Thesis Program Magister Manajemen. Program Pascasarjana Universitas Pasundan. Bandung.

Sumarwan, U. 2003. Perilaku Konsumen Teori dan Penerapannya Dalam Pemasaran. Jakarta: Ghalia Indonesia.

Tjiptono, F. 1997. Strategi Pemasaran. Edisi 1. Yogyakarta: Penerbit Andi.

Tjiptono, F. 2002. Manajemen Jasa. Yogyakarta: Penerbit Andi.
Tjiptono, F. 2004. Pemasaran Jasa. Malang: Bayumedia Publishing.

Tjiptono, F. 2005. Strategi Bisnis Pemasaran. Yogyakarta: Penerbit Andi.

U, Husein. 2003. Riset Pemasaran dan Perilaku Konsumen. Jakarta: Gramedia Pustaka Utama \& Jakarta Bussiness Research Center.

Wiyono, D. G. 2011. Merancang Penelitian Bisnis dengan Alat Analisis SPSS 17.0 dan SmartPLS 2.0. Yogyakarta: Unit Penerbit dan Percetakan STIM YKPN.

Vuuren, T. Van. 2012. Customer satisfaction, trust and commitment as predictors of customer loyalty within an optometric practice environment. Southern African Business Review Volume 16 Number 3.

Wilkie, L. 1994. Consumer Behavior, 4th. New York: John Wiley \& Sons.

Yanti, F., Karim, A., \& Wadud, M. (2018). Pengaruh Kualitas Pelayanan terhadap Kepuasan Konsumen pada Studio Ribka Foto Cabang Sekip di Palembang. Jurnal Ilmiah Ekonomi Global Masa Kini, 8(2), 47-52.

Zeithaml, VA., Parasuraman, A. \& Berry, LL. 1996. Delivering Quality Seervice, The Free Press, New York, N.Y. 